\title{
"UBER” nhân lực R\&D - Một cách tiếp cận trong thu hút và sử dụng nhân lực hiện nay
}

\author{
Đào Thanh Trường*, Nguyễn Thị Quỳnh Anh \\ Truờng Đại học Khoa học Xã hội và Nhân văn, ĐHQGHN,336 Nguyễn Trãi, Hà Nội, Việt Nam \\ Nhận ngày 17 tháng 01 năm 2017 \\ Chỉnh sửa ngày 27 tháng 02 năm 2017; Chấp nhận đăng ngày 22 tháng 3 năm 2017
}

Tóm tắt: Trước bối cảnh hội nhập quốc tế và xu thế toàn cầu hóa diễn ra ngày càng sâu sắc, nhiều quốc gia đã thay đổi tư duy về hoạch định và thực thi các chính sách về quản lý di động xã hội của nguồn nhân lực R\&D. Suốt một thời gian dài, các quốc gia lo sợ về hiện tượng "Chảy chất xám" và sự hình thành các "Cực nam châm" hút các luồng di động xã hội của nhân lực R\&D thì giờ đây, dưới tác động của Cuộc Cách mạng Công nghiệp thứ tư và sự lưu chuyển của nhân lực R\&D ngày càng trở nên linh hoạt, các nhà quản lý khoa học và công nghệ đang ngày càng chủ động đảm bảo ${ }^{2}$ các điều kiện để nhân lực $R \& D$ có thể lưu chuyển thông qua các phương thức tổ chức lao động có sự hỗ trợ của kỹ thuật số. Từ những phân tích về đặc điểm của nhân lực R\&D, di động xã hội của nhân lực $R \& D$ và những tác động của Cuộc Cách mạng Công nghiệp lần thứ tư, bài báo sẽ phân tích sự hình thành phương thức tổ chức lao động - UBER nhân lực R\&D, với một cách tiếp cận mới trong thu hút và sử dụng nhân lực khoa học và công nghệ (KH\&CN). Từ đó đưa ra những hàm ý chính sách trong quản lý di động xã hội của nguồn nhân lực R\&D hiện nay, với mục tiêu khuyến khích nguồn nhân lực này phát huy được năng lực sáng tạo và đóng góp cho sự phát triển của quốc gia trên mọi lãnh thổ và mọi lĩnh vực.

Tù khóa: Nghiên cứu \& Triển khai (R\&D), Nhân lực R\&D, di động xã hội của nhân lực R\&D, UBER nhân lực R\&D.

\section{Di động xã hội của nhân lực nghiên cứu và triển khai (R\&D)*}

\subsection{Khái niệm Nhân lực $R \& D^{12}$}

\footnotetext{
*Tác giả liên hệ. ĐT.: 84-913016429

Email: truongkhql@gmail.com

${ }^{1}$ Theo Từ điển Free Merriam - Webster (2010), chảy chất xám (brain drain hay human capital flight) là thuật ngữ dùng để chỉ vấn đề di cư quy mô lớn của nguồn nhân lực có kiến thức và kĩ thuật từ một nước qua những nước khác. Mặc dù thuật ngữ ban đầu dùng để chỉ những công nhân kĩ thuật đi qua những nước khác, ý nghĩa của nó đã mở rộng thành: "sự ra đi của những người có kiến thức hoặc có chuyên môn từ một quốc gia, khu vực kinh tế, hoặc các lĩnh vực khác, vì điều kiện sống hoặc tiền lương tốt hơn". ${ }^{1}$
}

Khi nói tới nhân lực R\&D, một số nghiên cứu chủ yếu tập trung phân tích về nhân lực khoa học và công nghệ $(\mathrm{KH} \& \mathrm{CN})$, tuy nhiên cần có sự phân biệt về nội hàm của hai khái niệm này để tránh nhầm lần. Trước hết, nguồn nhân lực $\mathrm{KH \& CN}$ là toàn bộ lực lượng lao động tham gia vào các hoạt động $\mathrm{KH} \& \mathrm{CN}$, trong đó nhân lực R\&D chiếm một lực lượng

Theo Luật di cư Quốc tế (2011) chảy chất xám được định nghĩa là "Việc xuất cu của nhũng cá nhân xuất sắc và được đào tạo tù nước gốc đến nuớc khác dẫn đến sụ suy yếu về nguồn kỹ năng của nước gốc"."

2 Ở đây có nhiều nhà nghiên cứu sử dụng từ quản lý (manage) hay điều khiển (control), xong trong phạm vi bài 
lao động đáng kể trong nguồn nhân lực KH\&CN (Xem Hình 1).

R\&D viết tắt của cụm từ Research and Experimental Development - thuật ngữ được dịch là Nghiên cứu và Triển khai ${ }^{3}$. Hoạt động nghiên cưu bao gồm: Nghiên cứu cơ bản và Nghiên cứu ứng dụng. Hoạt động Triển khai, còn gọi là triển khai thực nghiẹm, là sự vận dụng các lý thuyết để đưa ra các hình mẫu (prototype) với những tham số khả thi về $k \tilde{y}$ thuật. Hoạt động triển khai được chia thành hai loại: Triển khai trong phòng và triển khai bán đại trà. Hoạt động triển khai gồm 3 giai đoạn: Tạo vật mẫu (prototype), Tạo công nghệ còn gọi là giai đoạn "làm pilot", Sản xuất thử loạt nhỏ, còn gọi là sản xuất "Série 0 " (Loạt 0 ). Theo Vũ Cao Đàm, trong nền kinh tế thị trường, loại hoạt động này được thực hiện trước hết trong các trường đại học, trong các doanh nghiệp và cũng có cả các viện nghiên cứu độc lập.

Bảng 1. Hoạt động khoa học và công nghệ

\begin{tabular}{|c|c|c|c|c|c|}
\hline \multicolumn{2}{|l|}{$\begin{array}{l}\mathrm{R} \\
\text { (Research) } \\
\text { Nghiên cúu }\end{array}$} & \multirow{3}{*}{$\begin{array}{l}\text { D } \\
\text { Experimental } \\
\text { Development } \\
\text { Triển khai }\end{array}$} & \multirow{3}{*}{$\begin{array}{l}\mathrm{T} \\
\text { Transfer } \\
\text { Chuyển giao } \\
\text { tri thúc (bao } \\
\text { gồm chuyển } \\
\text { giao công } \\
\text { nghệ) }\end{array}$} & \multicolumn{2}{|c|}{$\begin{array}{l}\text { TD } \\
\text { Technology Development } \\
\text { Phát triển công nghệ }\end{array}$} \\
\hline \multirow{2}{*}{$\begin{array}{l}\text { Fundamental } \\
\text { Research } \\
\text { Nghiên cúu } \\
\text { co bản }\end{array}$} & \multirow[b]{2}{*}{$\begin{array}{l}\text { Applied } \\
\text { Research } \\
\text { Nghiên cứu } \\
\text { úng dụng }\end{array}$} & & & & \\
\hline & & & & $\begin{array}{l}\text { Extensitive } \\
\text { Development of } \\
\text { Technology hay } \\
\text { là Diffusion of } \\
\text { Technology } \\
\text { Mở rộng } \\
\text { công nghẹ }\end{array}$ & $\begin{array}{l}\text { Intensitive } \\
\text { Development of } \\
\text { Technology,hay } \\
\text { là Upgrading of } \\
\text { Technology } \\
\text { Nâng cấp } \\
\text { công nghẹ }\end{array}$ \\
\hline
\end{tabular}

Nguồn: [1]

Đặc trưng cơ bản nhất của hoạt động R\&D chính là tính mới - điều này đòi hỏi nhân lực R\&D luôn không ngừng tìm tòi và sáng tạo, từ đó hình thành nên sự dịch chuyển của các dòng nhân lực R\&D giữa các lĩnh vực, trong một quốc gia và từ quốc gia này sang quốc gia khác.

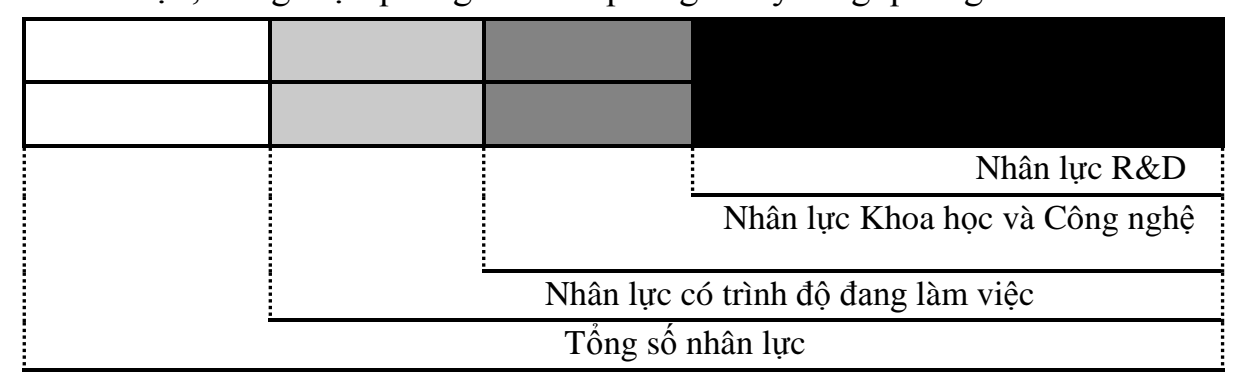

Hình 1. Quan hệ giữa nhân lực KH\&CNvà nhân lực R\&D [2] Nguồn: [3]

\footnotetext{
${ }^{3}$ R\&D: Research and Experimental Development, theo GS.Tạ Quang Bửu dịch là Nghiên cứu và Triển khai chứ không dịch là Nghiên cứu và Phát triển. Thuật ngữ Phát triển công nghệ được dùng cho cụm từ Technology Development bao gồm: Extensitive Development of Technology tức Diffusion of Technology (Mở rộng công nghệ) và Intensitive Development of Technology, tức Upgrading of Technology (Nâng cấp công nghệ). Thuật ngữ này người Trung Quốc goi là "Khai phát", người Nga gọi là "Razrabotka". Họ đều không dịch là "Phát triển". Chính sách tài chính cũng khác nhau cơ bản: "Triển khai" được cẩp vốn theo nguồn "Nghiên cứu và Triển khai" $(\mathrm{R} \& \mathrm{D})$, bán sản phẩm "Triển khai" được miễn thuế. Còn "Phát triển" thì phải phải dùng vốn vay và phải chịu thuế.
} 
Theo định nghĩa của nhóm tác giả, Nhân lự $R \& D$ là tập hợp những nhóm người tham gia vào các hoạt động nghiên cứu và triển khai với các chức năng: nghiên cứu sáng tạo, giảng dạy, quản lý, khai thác sử dụng và tác nghiệp, góp phần tạo ra tiến bộ của $\mathrm{KH} H \mathrm{CN}$, của sự phát triển sản xuất và xã hội. Nhóm nhân lực này thể hiện đặc trưng của hoạt động $R \& D$ : tính sáng tạo, tính mới hay đổi mới [3]. Nhân lực R\&D khác biệt với nhân lực có trình độ đang làm việc là ở đặc điểm: Nhân lực $R \& D$ có năng lực tư duy độc lập, sáng tạo và không ngừng đồi mới để tạo ra những sản phẩm tinh thần và vật chất có giá trị đối với xã hội, có thói quen tư duy độc lập. Yếu tố môi trường và điều kiện lao động ảnh hưởng rất lớn đến năng suất lao động của nhân lực $R \& D$. Vì vậy nhóm nhân lực này có $\mathrm{xu}$ hướng di động để tìm môi trường phát huy tối đa năng lực, bản thân họ cũng nhanh chóng thích nghi, điều chỉnh dễ dàng với các môi trường tại quốc gia khác [4]. Do mức độ nhu cầu ngày càng tăng của hàm lượng kiến thức trong sản xuất, tỷ lệ thuận với việc gia tăng nhu cầu của các quốc gia đối với nguồn nhân lực $\mathrm{R} \& \mathrm{D}$ nhằm thúc đẩy đổi mới trong hoạt động $\mathrm{KH} \& \mathrm{CN}$, từ đó làm tăng hiệu suất kinh tế tạo nên sự phát triển của các quốc gia. Theo định luật về "bảo toàn năng lượng", nhân lực R\&D không tự nhiên sinh ra, cũng không tự nhiên mất đi mà chỉ di chuyển từ nơi này sang nơi khác.

\subsection{Di động xã hội động xã hội của nhân lipc $R \& D$}

Di động xã hội (Social Mobility) của nhân lực $R \& D$ có thể được hiểu là sự dịch chuyển về vị trí xã hội của cá nhân hay một nhóm nhân lực; sự thay đổi đi lên hoặc đi xuống về vị thế xã hội giữa các cá nhân/nhóm nhân lực khác nhau trong hệ thống phân tầng xã hội trong khoa học, sự chuyển dịch từ một địa vị này đến một địa vị khác trong cơ cấu của hoạt động khoa học và công nghệ. Trong đó, các loại hình di động xã hội đặc trưng của nhân lực R\&D bao gồm: Di động xã hội không kèm di cư; Di động xã hội kèm di cư; Di động dọc; Di động ngang.
Xét đến cùng hiện tượng di động xã hội trong khoa học xảy ra do sự không đồng đều về CƠ HÔI trong khoa học. Cơ hội này được thể hiện việc đáp ứng các điều kiện về vật chất và phi vật chất nhằm thỏa mãn các $\mathbf{N H U ~ C A ̂ ̀ U ~ C A ́ ~}$ NHÂN của nhân lực $R \& D$, trong đó đặc biệt nhấn mạnh về nhu cầu thứ năm và thứ sáu trong tháp nhu cầu của Maslow ${ }^{4}$ : Nhu cầu hoạt động và Nhu cầu hiểu biết. Sự dịch chuyển giúp nhân lực $R \& D$ tìm được môi trường phát huy tài năng và công việc họ yêu thích, điều này cũng đồng nghĩa với sự phát triển không ngừng của các ngành khoa học. Vì vậy, trong việc quản lý nhân lực $R \& D$, do đặc điểm lao động là độc lập và linh hoạt, nên không thể ép nhà nghiên cứu "ngồi một chỗ" để làm nghiên cứu, điều này khác với hoạt động công nghệ thì đặc điểm lao động luôn có sự ràng buộc giữa các khâu, kỷ luật công nghệ rất nghiêm ngặt, nên người điều hành công nghệ cũng phải chấp hành những kỷ luật không được phép rời khỏi vị trí công việc [1]. Di động xã hội là một đặc tính tất yếu của nhóm nhân lực đặc biệt này .

Đối với các quốc gia đang phát triển như Việt Nam hiện nay, nhân lực R\&D là một trong những thành tố quan trọng cốt lõi của hệ thống đổi mới quốc gia (National Innovation System).Trong chính sách khoa học, công nghệ và đổi mới (Science, Technology and Innovation), chính sách phát triển nhân lực R\&D bao gồm: thu hút các dòng chảy của nhân lực giữa các lĩnh vực chuyên môn (discipline mobility); định hướng dòng chảy nhân lực giữa các lĩnh vực chuyên môn; thu hút nhân lực giữa các khu vực, quốc gia, địa phương; đào tạo nhân lực luôn là một trong những trọng tâm chính sách nhân lực của các quốc gia. [5]

Di động xã hội của nhân lực R\&D đã và đang đặt ra những bài toán trong hoạch định các chính sách thu hút nhân lực khoa học và công

\footnotetext{
4 Tháp nhu cầu của Abraham Maslow): Tầng thú nhất: Nhu cầu sinh hoc, Tầng thư hai: Nhu cầu an ninh, Tầng thứ ba: Nhu cầu tình cảm

Tầng thư tu: Nhu cầu kính trọng, Tầng thứ năm: Nhu cầu hoạt động, Tầng thứ sáu: Nhu cầu hiểu biết, Tầng thứ bảy: Nhu cầu thẩm mĩ
} 
nghệ nói chung, cũng như đặt ra câu hỏi: Công cu nào sẽ giúp nhân lục $R \& D$ thưc sụ tìm được thi truoòng cho chính bản thân ho khi đặc tính di động xã hội của nhóm nhân lực này ngày càng phổ biến? Những gợi suy này giúp nhóm tác giả hình thành giả thuyết về sự ra đời của một phương thức tổ chức lao động mới của nhân lực R\&D với sự hỗ trợ đặc lực của các thành tựu kỹ thuật số trong bối cảnh Cuộc Cách mạng Công nghiệp lần thứ tư đang diễn ra mạnh mẽ hiện nay.

\subsection{Di động xã hội của nhân lục $R \& D$ duơoi tác động của các cuộc Cách mạng Công nghiệp}

Nền KH\&CN hiện nay đang góp phần đẩy nhanh tính di động xã hội, "nhịp sống của một xã hội tốc độ" (Fast Society) mà theo Alvin Tofler "Nó ảnh hưởng nhận thưc của chúng ta về thời gian, cách mạng hóa nhịp điệu cuộc sống hàng ngày" [6]. Trong một "Thế giới phẳng", , sự bùng nổ của công nghệ thông tin và chính sách mở cửa của nền kinh tế các quốc gia và khu vực, chảy chất xám và thu hút chất xám trở thành "đòn bẩy" cho việc lưu thông tri thức khoa học và thành tựu công nghệ trở nên nhanh chóng với chi phí thấp hơn. Theo Mai Hà, những yếu tố có ảnh hưởng quyết định tới tốc độ phát triển, đó là: Thứ nhất, Văn hóa vì sự phát triển là nền tảng cho phát triển; Thú hai, Môi trường phát triển cạnh tranh lành mạnh là yếu tố động lực - quyết định cho sự phát triển; Thư $b a$, Lao động sáng tạo và tri thức khoa học và công nghệ là công cụ đắc lực cho phát triển [7].

Lịch sử đã chứng kiến ba cuộc Cách mạng Công nghiệp [8] lớn, tác động mạnh mẽ đến lịch sử phát triển khoa học và công nghệ của nhân loại. Mỗi Cuộc Cách mạng đánh dấu sự ra đời của các thành tựu khoa học và công nghệ nổi bật, góp phần tạo ra những bước phát triển

\footnotetext{
${ }^{5}$ Thế giới phẳng (Tiếng Anh: The world is flat) là một tác phẩm của Thomas Friedman - một biên tập viên chuyên mục ngoại giao và kinh tế của tạp chí New York Times có những tác phẩm và công trình nghiên cứu về vấn đề toàn cầu hoá.
}

nhảy vọt của các lĩnh vực công nghệ và sự bứt phá của các quốc gia trong cuộc chạy đua công nghệ toàn cầu, tác động mạnh mẽ đến sự di chuyển mạnh mẽ của các luồng di động của nhân lực khoa học. Xu hướng này sau đó được các nhà nghiên cứu nhìn nhận dưới góc độ đó là biểu hiện của lưu thông khoa học giữa các quốc gia, nó đem lại sự đa dạng hóa khoa học và góp phần thúc đẩy quá trình hợp tác trong phát triển $\mathrm{KH} \& \mathrm{CN}$ giữa các quốc gia và tiếp tục tạo ra những thành tựu trong lĩnh vực khoa học và công nghệ.

Trong những 20 của thế kỷ 21, Cuộc Cách mạng Công nghiệp lần thứ Tư - đã tiếp tục khuyến khích các quốc gia cho ra đời những loại hình sản phẩm, dịch vụ khoa học và công nghệ tốt nhất, tiện lợi nhất mà vẫn đảm bảo tiết kiệm thời gian và chi phí. Một trong những xu hướng lớn của Cuộc Cách mạng công nghiệp lần thứ tư hiện nay là sự phát triển của kỹ thuật số, sự hội tụ giữa ứng dụng vật lý và ứng dụng kỹ thuật số là sự xuất hiện Internet của vạn vật (Internet of Things- IoT) ${ }^{\dot{6}}$. Điều này thúc đẩy sự hình thành Cyber-Physical Systems, có thể tạm gọi là hệ thống sản xuất thực-ảo. ${ }^{7}$ Theo lý thuyết kinh tế ${ }^{8}$ cho rằng người sở hữu tư liệu sản xuất là người có quyền lực, ngày nay sự phát triển của CPS trong Cuộc cách mạng công nghiệp thứ tư đã chứng minh quyền lực thông tin đang lấn lướt quyền lực tài chính. Quyền lực nắm giữ tư liệu sản xuất bị thay thế bởi quyền lực thông tin. (Xem Bảng 2).

\footnotetext{
http://hame.org.vn/cuoc-cach-mang-cong-nghiep-lanthu-tu-boi-canh-cac-xu-huong-lon-va-nhung-san-phamdien-hinh.html

${ }^{7}$ (CyberPhysical Systems - CPS) lần đầu tiên được Tiến sĩ James Truchard, Giám đốc điều hành của National Instruments, giới thiệu vào năm 2006.

${ }^{8}$ Xem thêm Post Capitalism, Paul Mason
} 
Bảng 2. Các cuộc Cách mạng công nghiệp và di động xã hội của nguồn nhân lực khoa học và công nghệ

\begin{tabular}{|c|c|c|c|c|}
\hline STT & $\begin{array}{l}\text { Cuộc } \\
\text { Cách mạng } \\
\text { công nghiệp }\end{array}$ & Thời gian & Mô tả ngắn gọn & $\begin{array}{l}\text { Di động xã hội của } \\
\text { nhân lực khoa học và công nghệ }\end{array}$ \\
\hline 1 & $\begin{array}{l}\text { Cuộc cách } \\
\text { mạng công } \\
\text { nghiệp lần thứ } \\
1 \text { (The First } \\
\text { Industrial } \\
\text { Revolution) }\end{array}$ & $\begin{array}{l}\text { Từ khoảng } \\
1780 \text { đến } \\
\text { khoảng } \\
\text { 1820-1840 }\end{array}$ & $\begin{array}{l}\text { - Đánh dấu bằng sự ra đời của } \\
\text { động cơ hơi nước, rồi sau đó là } \\
\text { động cơ đốt trong, mở rộng sử } \\
\text { dụng nhiên liệu than đá, xây dựng } \\
\text { các tuyến đường sắt, mở ra kỷ } \\
\text { nguyên sản xuất cơ khí và phát } \\
\text { triển giao thương.. } \\
\text { - Đây còn được coi là cuộc cách } \\
\text { mạng cơ cấu ngành nghề. Cụ thể } \\
\text { là sự phát triển của máy móc và } \\
\text { những ứng dụng rộng rãi của nó } \\
\text { trong nền sản xuất, đã đưa các } \\
\text { lĩnh vực công nghiệp nặng lên } \\
\text { một tầm cao mới, bên cạnh vị trí } \\
\text { đã được khẳng định của các lĩnh } \\
\text { vực công nghiệp nhẹ. Tiêu chí } \\
\text { quan trọng nhất của cuộc cách } \\
\text { mạng kỹ thuật lần này là máy } \\
\text { móc thay thế công cụ thủ công }\end{array}$ & $\begin{array}{l}\text { - Chưa gây ra đột biến nào về } \\
\text { LLSX cho đến khi xuất hiện máy } \\
\text { công cụ tại Anh } \\
\text { - Thành tựu của Cuộc Cách } \\
\text { mạng công nghiệp lần thứ nhất } \\
\text { đã hình thành luồng di động của } \\
\text { các nhà khoa học tới quốc gia } \\
\text { "miền đất hứa" của nghiên cứu } \\
\text { khoa học thời điểm này như } \\
\text { Anh, Pháp, đặc biệt là sự ra đời } \\
\text { của mô hình đại học nghiên cứu } \\
\text { (Đại học Humbolt) }\end{array}$ \\
\hline 2 & $\begin{array}{l}\text { Cuộc cách } \\
\text { mạng công } \\
\text { nghiệp lần thứ } \\
2 \text { (The Second } \\
\text { Industrial } \\
\text { Revolution) }\end{array}$ & $\begin{array}{l}\text { Từ } 1870 \text { đến } \\
\text { khoảng } \\
\text { những năm } \\
\text { thập niên } \\
\text { 1950, mở ra } \\
\text { kỷ nguyên } \\
\text { sản xuât } \\
\text { hàng loạt. }\end{array}$ & $\begin{array}{l}\text { Với sự ra đời của máy phát điện, } \\
\text { đèn điện, động cơ điện, mở rộng } \\
\text { việc sử dụng điện năng trong sản } \\
\text { xuất }\end{array}$ & $\begin{array}{l}\text { - Di cư quốc tế (trong đó có sự } \\
\text { hình thành của các luồng di động } \\
\text { của nhân lực khoa học gắn với } \\
\text { sự hình thành thị trường tư bán ở } \\
\text { các nước phát triển hay sự thâm } \\
\text { nhập của kinh tế tư bản vào thị } \\
\text { trường các nước đang phát triển. } \\
\text { - Hoa Kỳ dần trở thành điểm đến } \\
\text { của các luồng di động nhân lực } \\
\text { KH\&CN từ khắp các quốc gia } \\
\text { trên thế giới. }\end{array}$ \\
\hline 3 & $\begin{array}{l}\text { Cuộc cách } \\
\text { mạng công } \\
\text { nghiệp lần thứ } \\
3 \text { (The Third } \\
\text { Industrial } \\
\text { Revolution) }\end{array}$ & $\begin{array}{l}\text { Từ giữa thế } \\
\text { kỷ } 20 \\
(1969) \text {, tiếp } \\
\text { sau những } \\
\text { thành tựu } \\
\text { lớn từ lần } \\
\text { thứ } 3 \text { để lại }\end{array}$ & $\begin{array}{l}\text { - Đặc điểm của cuộc cách mạng } \\
\text { này là lần đầu tiên con người đã } \\
\text { sáng tạo ra một loại máy có thể } \\
\text { thay thế một phần quan trọng của } \\
\text { lao động trí óc- đó là máy tính } \\
\text { (chứ không như các loại máy cơ } \\
\text { khí và điện khí chỉ thay thế lao } \\
\text { động cơ bắp). Sự ra đời của chất } \\
\text { bán dẫn đã dẫn tới việc sáng chế } \\
\text { ra các siêu máy tính (thập niên }\end{array}$ & $\begin{array}{l}\text { - Cách mạng công nghiệp lần thứ } \\
3 \text {, nổi lên tại các quốc gia phát } \\
\text { triển nhất thế giới, bước ngoặc } \\
\text { lịch sử này phát hiện vào những } \\
\text { năm 60s của thế kỷ } 20 \text { khi mà sồ } \\
\text { người làm việc văn phòng và } \\
\text { làm dịch vụ vượt hơn số lượng } \\
\text { công nhân. } \\
\text { - Trong những năm cuối thế kỷ } \\
20 \text { đầu thế kỷ } 21 \text {, cuộc cạnh }\end{array}$ \\
\hline
\end{tabular}




\begin{tabular}{|c|c|c|c|c|}
\hline & & & $\begin{array}{l}\text { 1960), máy tính cá nhân (thập } \\
\text { niên 1970 và 1980) và Internet } \\
\text { (thập niên 1990). } \\
\text { - Cũng trong thời kỳ này, chính } \\
\text { con người đã phát hiện một quy } \\
\text { luật quan trọng của thiên nhiên là } \\
\text { Quy luật tồn tại của hệ sinh thái, } \\
\text { từ đó biết tôn trọng tính đa dạng } \\
\text { sinh học trong nhiệm vụ bảo vệ } \\
\text { môi trường thiên nhiên cũng } \\
\text { chính là bảo vệ sự phát triển bền } \\
\text { vững của loài người trong môi } \\
\text { trường tự nhiên. }\end{array}$ & $\begin{array}{l}\text { tranh giữa các quốc gia thực chất } \\
\text { diễn ra trong lĩnh vực khoa học } \\
\text { và công nghệ cao mà nhân lực } \\
\text { KH\&CN là nguồn lực cơ bản } \\
\text { giúp rút ngắn khoảng cách phát } \\
\text { triển. Tình trạng chảy máu chất } \\
\text { xám trở nên ngày càng phổ biến } \\
\text { với nhiều hình thái khác nhau tại } \\
\text { các quốc gia. } \\
\text { - Hiện tượng "Thất nghiệp công } \\
\text { nghệ" } 9 \text { trở nên phổ biến tại một } \\
\text { số lĩnh vực mà trong đó máy } \\
\text { móc thay thế dần công việc của } \\
\text { con người. }\end{array}$ \\
\hline 4 & $\begin{array}{l}\text { Cuộc cách } \\
\text { mạng công } \\
\text { nghiệp lần thứ } \\
4 \text { (The Fourth } \\
\text { Industrial } \\
\text { Revolution) }^{10}\end{array}$ & $\begin{array}{l}\text { Giữa thập kỷ } \\
\text { thứ hai của } \\
\text { thế kỷ } 21 \text {. }\end{array}$ & $\begin{array}{l}\text { - Từ Cuộc cách mạng công } \\
\text { nghiệp lần thứ tư, sự hội tụ giữa } \\
\text { ứng dụng vật lý và ứng dụng kỹ } \\
\text { thuật số là sự xuất hiện Internet } \\
\text { của vạn vật (Internet of Things, } \\
\text { IoT). Mô tả đơn giản nhất, có thể } \\
\text { coi IoT là mối quan hệ giữa vạn } \\
\text { vật (các sản phẩm, dịch vụ, địa } \\
\text { điểm, v.v...) và con người thông } \\
\text { qua các công nghệ kết nối và các } \\
\text { nền tảng khác nhau. } \\
\text { - Đây là xu hướng kết hợp giữa } \\
\text { các hệ thống ảo và thực thể, vạn } \\
\text { vật kết nối Internet (IoT) và các } \\
\text { hệ thống kết nối Internet (IoS). } \\
\text { Điều này sẽ thay đổi hoàn toàn } \\
\text { cách thức mà chúng ta quản lý } \\
\text { chuỗi cung ứng bằng cách cho } \\
\text { phép chúng ta giám sát và tối ưu } \\
\text { hóa tài sản và các hoạt động đến } \\
\text { một mức rất chi tiết. }\end{array}$ & $\begin{array}{l}\text { - Hình thành Cyber-Physical } \\
\text { Systems } \\
\text { - Dự báo gây ra nguy cơ phá vỡ } \\
\text { thị trường lao động, ngày càng } \\
\text { phân hóa theo hai nhóm: Nhóm } \\
\text { kỹ năng thấp/trả lương thấp và } \\
\text { nhóm kỹ năng cao/trả lương cao. } \\
\text { - Siêu tự động hóa và siêu kết } \\
\text { nối có thể nâng cao năng suất } \\
\text { những công việc hiện tại hoặc } \\
\text { tạo ra nhu cầu về những công } \\
\text { việc hoàn toàn mới } \\
\text { - Sự ra đời của "robots" - robot } \\
\text { hợp tác có khả năng di chuyển } \\
\text { và tương tác, } 23 \text { sẽ giúp các công } \\
\text { việc kỹ năng thấp đạt năng suất } \\
\text { nhảy vọt. } \\
\text { - Dự báo về sụ hình thành của } \\
\text { Blockchain trong thu hút và sủ } \\
\text { dụng nhân lực R\&D }\end{array}$ \\
\hline
\end{tabular}

Nguồn: Tổng hợp của nhóm tác giả

\footnotetext{
9 Thất nghiệp công nghệ: Technological unemployment.

${ }^{10}$ Cách mạng công nghiệp lần 4, bước ngoặc lịch sử này vào năm 2011 tại Hội chợ Công nghệ Hannover ở Cộng hòa liên bang Đức thuật ngữ "Công nghiệp 4.0" lần đầu tiên được đưa ra. Đến năm 2012, thuật ngữ "Công nghiệp 4.0" được sử dụng cho giới nghiên cứu và các hiệp hội công nghiệp hàng đầu của Đức nhằm cải thiện quy trình quản lý và sản xuất trong các ngành chế tạo thông qua "điện toán hóa". Ngày 20/01/2016, tại Diễn đàn kinh tế thế giới đã khai mạc với chủ đề "Làm chủ Cuộc cách mạng công nghiệp lần thứ tư". Từ đó, đến nay, thuật ngữ "Công nghiệp 4.0" được sử dụng rộng rãi trên thế giới.

${ }_{11}^{11} \mathrm{http} / / / g e n k . v n / c a c h-m a n g-c o n g-n g h i e p-l a n-t h u-t u-d a n g-t h a y-d o i-t h e-g i o i-n h u-t h e-n a o-20160406171025427 . c h n$

${ }^{12} \mathrm{http}$ ://hame.org.vn/cuoc-cach-mang-cong-nghiep-lan-thu-tu-boi-canh-cac-xu-huong-lon-va-nhung-san-pham-dienhinh.html
} 


\section{UBER nhân lực R\&D: Một cách tiếp cận mới}

\subsection{Sự hình thành của phương thức tổ chức lao động: UBER nhân lục $R \& D$}

$U B E R^{13}$ nhân lục $R \& D$ là một phương thức tổ chức lao động được nhóm tác giả tạm đặt tên, theo tên của một sản phẩm của công nghệ phần mềm đặt xe thông qua điện thoại thông minh trên nền tảng google map có sử dụng dịch vụ định vị toàn cầu. UBER nhân lực $R \& D$ là phương thức tổ chức lao động hình thành các giao dịch về thu hút và sử dụng nhân lực $R \& D$ hiệu quả, minh bạch thông qua blockchain.

Hình thức tổ chức lao động này sẽ tạo ra một cơ sở dữ liệu trong thu hút và cung ứng nhân lực, thực hiện các nhiệm vụ khoa học và công nghệ theo đặt hàng, hạn chế phương thức quản lý nhân lực khoa học và công nghệ phụ thuộc vào các hợp đồng biên chế. Đồng thời, xóa bỏ những tiếp cận một chiều về di động xã hội của nhân lực khoa học và công nghệ về hiện tượng “chảy máu chất xám", mà cung cấp một loại hình dịch vụ duy trì và chủ động đảm bảo sự lưu chuyển của các dòng nhân lực thực hiện các nhiệm vụ khoa học khác nhau, tùy năng lực trình độ của mỗi cá nhân/nhóm nghiên cứu trong việc triển khai các giao dịch với khách hàng. Từ đó, khẳng định uy tín của cá nhân, nhóm nghiên cứu và đưa chất lượng nghiên cứu lên làm tiêu chí đầu tiên trong cung ứng giao dịch về nhân lực trong tương lai.

Một lưu ý, đối tượng của phương thức tổ chức lao động này chỉ phù hợp với nhân lực R\&D mà không thể tính đến nhân lực "phát triển công nghệ” với lý do, sự di chuyển của

\footnotetext{
${ }^{13}$ Uber là một ứng dụng (phần mềm) xây dựng theo kiểu hệ thống toàn cầu, như một cỗ máy điều tiết xe tự động chứ không như các tổng đài taxi. Theo đó, hành khách đặt xe và tài xế được kết nối với nhau bằng điện thoại thông minh qua phần mềm Uber được cài trên điện thoại di động của hành khách và tài xế. Tài xế và hành khách biết rõ vị trí của nhau dựa trên định vị toàn cầu GPS của điện thoại... ${ }^{13}$. Uber đã chứng minh được những ưu điểm vượt trội về tính kinh tế, tính minh bạch và đáp ứng nhu cầu tiện dụng, văn minh so với loại hình dịch vụ vận tải truyền thống.
}

nhân lực phát triển công nghệ có thể gây gián đoạn trong vận hành dây chuyền công nghệ và nhân lực phát triển công nghệ có thể bị sa thải hoặc can án nếu di chuyển môt cách tùy tiện.

\section{* Vai trò của Thị truòng tri thức trục tuyến}

Động lực chính của cuộc cách mạng công nghiệp lần thứ tư là sự thay đổi trong kỳ vọng của người dùng (sản phẩm theo yêu cầu và giao hàng nhanh chóng), cùng với sự hội tụ của các công nghệ mới như "Internet kết nối mọi thứ" (Internet of Things). Dưới tác động của Cuộc cách mạng này, giao dịch cung ứng không chỉ là các sản phẩm hàng hóa, dịch vụ phục vụ đời sống mà còn dẫn tới sụ ra đời tất yếu của thị truoòng tri thức trực tuyến - nơi giao dịch của các cá nhân, nhóm các nhà khoa học chủ động di động xã hội để tìm kiếm cơ hội và môi trường làm việc phù hợp. Thị trường tri thức trực tuyến (Online Knowledge Market) [9] - nơi tồn tại các giao dịch của các đối tượng: khách hàng (có nhu cầu) - các cá nhân/nhóm nghiên cứu có khả năng đối ứng về tri thức khoa học và công nghệ - các đơn vị trung gian (dịch vụ) xuyên biên giới hay trong chính lãnh thổ của một quốc gia.

Địa điểm thị trường tri thức trực tuyến quản lý các nền tảng - theo người sử dụng là những website - tạo điều kiện cho liên lạc, kết nối và giao dịch tri thức sáng tạo giữa các cá nhân, các tổ chức. Nhìn chung, địa điểm thị trường tri thức trực tuyến là các đơn vị độc lập không liên kết với những người sở hữu tri thức hay những người tìm kiếm tri thức, nhằm tránh những xung đột lợi ích tiềm tàng...Bằng cách kết nối những người xa lạ với nhau, không bị ràng buộc bởi các liên kết tin cậy trước đó, mô hình này đánh dấu một sự khởi đầu sắc nét từ các hoạt động đã được chấp nhận, trong đó các hoạt động giao dịch có xu hướng xuất hiện trong phạm vi gần (địa lý, xã hội) của tổ chức... Thị trường trực tuyến thường đòi hỏi tiêu chuẩn hóa hình thức trình bày thông tin về các tri thức cần mua và tri thức cung cấp. Nếu không, các nền tảng sẽ không cung cấp được các dịch vụ với chi phí thấp hơn đáng kể so với tổng thể các nỗ lực tìm kiếm riêng lẻ, không có sự kết hợp. [10] 
Sự phát triển của Thị trường tri thức trực tuyến tạo điều kiện cho UBER nhân lực R\&D hình thành như một hệ lụy tất yếu. Theo đó, kỹ thuật số sẽ là công cụ để nhân lực khoa học và công nghệ di động xã hội và tìm thị trường cho chính mình, thay vì trông chờ những nhiệm vụ nghiên cứu của tổ chức giao cho. Sự thay đổi này có thể dẫn tới những bước ngoặt trong việc hình thành các tổ chức ảo, trong đó nhân lực $R \& D$ được độc lập tham gia và tìm kiếm cơ hội làm việc mà không chịu sự ràng buộc của các thiết chế hành chính.

* Liệu có thể hình thành Block chain trong cung ưng nhân lục R\&D theo nhu cầu?

Theo Vũ Cao Đàm, một trong những công cụ gắn kết các giao dịch ưu việt của cuộc Cách mạng Công nghiệp lần thứ tư là Block chain. Theo Don \& Alex Tapscott, tác giả của Blockchain Revolution (2016): "Blockchain là một sổ sách kỹ thuật số không hư hỏng của các giao dịch kinh tế có thể được lập trình để ghi lại không chỉ các giao dịch tài chính mà hầu như tất cả mọi thứ có giá trị” ${ }^{14}$. Blockchain, thường được mô tả như là một "đầu mối phân phối”, là một giao thức an toàn trong đó một mạng các máy tính cùng nhau xác thực một giao dịch trước khi được lưu trữ và chấp thuận. Công nghệ làm cơ sở cho blockchain tạo ra sự tin tưởng bằng cách cho phép những người không biết nhau (về căn bản không thể tin tưởng) cộng tác với nhau mà không cần phải thông qua một nhà chức trách trung tâm trung lập - nghĩa là một người ủy thác hoặc đầu mối trung tâm. Về bản chất, blockchain là giao thức có khả năng chia sẻ, lập trình, mã hóa an toàn do đó trở nên đáng tin cậy bởi không có bất kì người dùng nào có thể điều khiển được và có thể được kiểm tra bởi tất cả mọi người. Tạo mối liên hệ giữa con người mà không có sự quản lý hành chính. Theo wikipedia, Blockchains đã được mô tả như là một giao thức trao đổi giá trị. Sự trao đổi giá trị dựa trên blockchain này có thể được

\footnotetext{
14 "The blockchain is an incorruptible digital ledger of economic transactions that can be programmed to record not just financial transactions but virtually everything of value."
}

hoàn thành nhanh hơn, an toàn và rẻ hơn so với các hệ thống truyền thống ${ }^{15}$.

Hoàn toàn có thể dự báo về sự xuất hiện Blockchain trong việc phân phối sử dụng nhân lực $\mathrm{R} \& \mathrm{D}$ với sự phát triển của kỹ thuật số và do nhu cầu di động của nhân lực R\&D. Tất nhiên, sự hình thành của Blockchain sẽ hoàn toàn khác với các dịch vụ cung ứng nhân lực thông thường thông qua các website tìm kiếm việc làm hiện nay, ở tính kết nối lưu động và sự phân loại nguồn lực qua vị trí địa lý và lĩnh vực nghiên cứu. Các giao dịch thông qua blockchain có thể là giao dịch thuê ảo các nhân lực thực hiện nghiên cứu căn cứ theo tiêu chí khách hàng yêu cầu và mục tiêu nghiên cứu của nhiệm vụ nghiên cứu mà không thông qua việc các nhân lực $R \& D$ có bao nhiều bằng cấp. Blockchain được vận hành trên cơ sở không đánh giá bằng cấp của nhân lực $R \& D$ mà chỉ phụ thuộc vào Cung và Cầu của thị trường trí thức trực tuyến.

* Các thành phần tham gia UBER nhân lực $R \& D$

UBER R\&D (Sü dụng công cu blockchain trong phân phối và quản lý giao dịch): Chủ thể trung gian đáp ứng Cung - Cầu về nhân lực R\&D trên cơ sở vận hành blockchain. Blockchain đảm bảo tính bảo mật và thông tin của các đối tượng tham gia. Chủ thể trung gian cung ứng sẽ được hưởng chi phí từ hoạt động giao dịch thông tin và thu nhận phản hồi kêt quả các giao dịch nghiên cứu theo đặt hàng, cung cấp hệ thống thông tin, xây dựng ngân hàng dữ liệu các giao dịch này cho các cơ quan quản lý thông tin khoa học, cung cấp dữ liệu cho các bên liên quan trong trường hợp xảy ra tranh chấp. Chủ thể cung ứng dịch vụ sẽ cung cấp cho bên Cầu (khách hàng) các đối tượng cung ứng tiềm năng và bên Cung những đối tượng khách hàng đang muốn đặt hàng các nhiệm vụ nghiên cứu thông qua Blockchain.

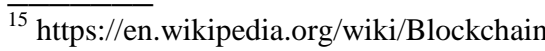


Sơ đồ 1. Thành phần tham gia UBER nhân lực R\&D

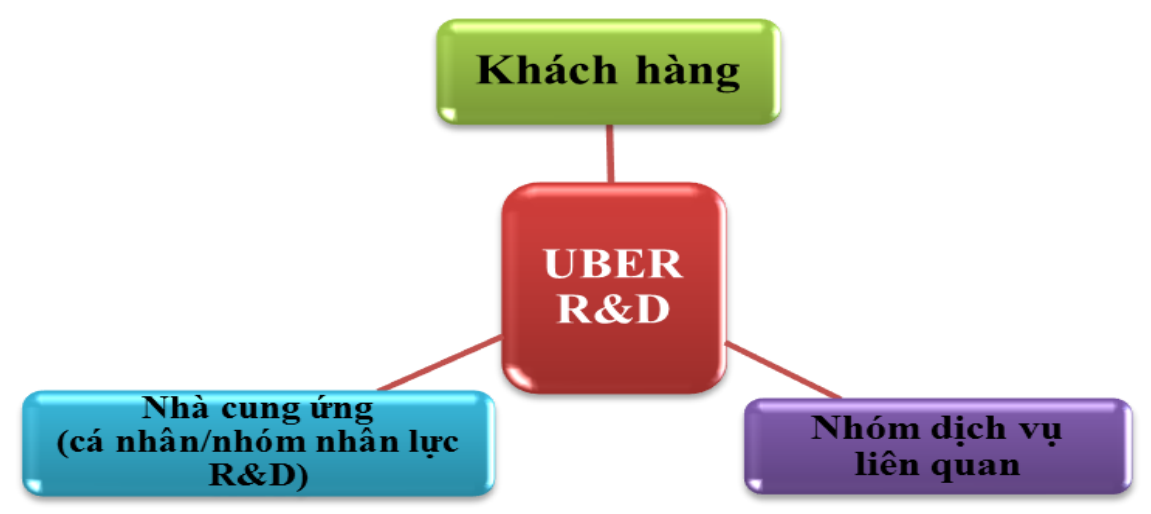

Đối tương khách hàng (Cá nhân hoặc tổ chưcc): Người đặt hàng, có quyền truy cập vào hệ thống, thông qua chủ thể trung gian để tìm nhân lực $R \& D$ tiềm năng theo chuyên môn hoặc theo vị trí địa lý thực hiện các đơn hàng nghiên cứu.

Nhà cung úng (cá nhân/nhóm nhân lực $R \& D)$ : Đảm bảo về phương tiện thực hiện các đơn đặt hàng (về nguồn lực) qua các giao dịch cam kết được Blockchain ghi lại do phía khách hàng xác nhận. Sau khi hai bên cùng xác nhận, Blockchain lưu giữ các cam kết và đảm bảo về chu trình hoàn tất thủ tục thanh toán trước khi bàn giao sản phẩm nghiên cứu.

Nhóm dịch vu liên quan: Để các giao dịch thành công, cần xây dựng một hệ thống thông tin khoa học và cập nhật các yêu cầu giao dịch từ khắp các địa phương, cá nhân, tổ chức theo từng tiêu chí phân loại riêng. Nhóm này có thể là nhóm kỹ thuật viên, nhóm văn phòng, nhóm marketing....phục vụ các giao dịch cung ứng nhân lực R\&D theo đặt hàng.

Bên cạnh chi phí dịch vụ cung ứng, khách hàng có thể giao dịch kèm các quyền lợi khác cho nhóm cung ứng - các nhà khoa học. Bởi lẽ, các kết quả nghiên cứu hay khảo sát thực tiễn đôi khi tiến hành rất tốn kém mà người nghiên cứu không thể thực hiện, trong trường hợp này, khách hàng có thể đề xuất các lợi ích về mặt khoa học để thu hút sự tham gia và cung ứng dịch vụ của các nhóm nghiên cứu thậm chí với kinh phí thấp. Điểm ưu việt của hoạt động cung ứng này chính là mang tới lợi ích cho khách hàng, đồng thời cũng đem lợi ích thiết thực cho nhà cung ứng - những người tìm tòi, sáng tạo và có mong muốn nghiên cứu và xuất bản các nghiên cứu về chuyên môn. Trong quá trình giao dịch, nhóm cung ứng dịch vụ hoàn toàn có thể đề xuất thêm các lợi ích phi vật chất từ khách hàng khi họ triển khai các nhiệm vụ khoa học.

Như vậy phương tiện UBER nhân lực R\&D sẽ có thể phần nào giải quyết câu hỏi: Công cụ nào nhân lực $R \& D$ tìm được thị trường cho chính bản thân họ? - Giải pháp kỹ thuật số với việc hình thành phương thức tổ chức lao động thông minh - UBER nhân lực R\&D có thể là một sự lựa chọn cho các nhà quản lý KH\&CN trong thúc đẩy di động xã hội nhân lực $R \& D$ và hơn hết là sự phát triển của hoạt động nghiên cứu. Tuy nhiên, sự hình thành của phương thức tổ chức lao động này sẽ bị chi phối bởi nhiều yếu tố, trong phạm vi bài viết xin đưa ra một vài phân tích thông qua công cụ SWOT.

Theo phân tích này, các nhà quản lý khoa học và công nghệ có thể tạm thời đưa ra các chiến lược cụ thể cho việc thúc đẩy di động xã hội của nhân lực $R \& D$, dựa trên các chiến lược: SO, ST, WO hay WT, tùy điều kiện thực tiễn. 
Bảng 2. Phân tích SWOT UBER nhân lực R\&D tại Việt Nam

ĐIÊMM MẠNH (S)
- Phát triển thị trường tri thức trực tuyến và nhân rộng
các mô hình UBER nhân lực R\&D liên quốc gia, liên
khu vực (cung cấp miễn phí cơ hội làm nghiên cứu tại
địa phương, tạo điều kiện cho nhân lực R\&D nước
ngoài đến làm việc và công bố về các nghiên cứu có sự
tham gia của các nhóm cung ứng dịch vụ nội địa).
- Thúc đẩy di động xã hội của nhân lực khoa học và
công nghệ, đây nhanh quá trình quốc tế hóa nguồn
nhân lực R\&D nội địa, thúc đẩy sự hình thành các lĩnh
vực nghiên cứu mới và sự phát triển của các ngành ưu
tiên

Mang lại thu nhập chính đáng cho nhân lực khoa học và công nghệ, xóa bỏ tư tưởng học phiệt trong nghiên cứu; giảm thiểu dần và dẫn tới chấm dứt tình trạng biên chế cồng kềnh, dựa trên tiêu chí bằng cấp trong sử dụng nhân lực nghiên cứu

\section{ĐIỂM YẾU (W)}

Hành lang pháp lý chưa thực sự đảm bảo tính an toàn cho giao dịch nếu trong trường hợp kinh phí giao dịch quá lớn trong khi trách nhiệm và quyền hạn của cơ quan quản lý có hạn

Nhà quản lý cung ứng không tham gia được quá trình định giá nhiệm vụ nghiên cứu qua hồ sơ của đối tác cung ứng (như số km trong UBER)

\begin{tabular}{l} 
CƠ HỘI $(\mathrm{O})$ \\
\hline $\begin{array}{l}\text { Cuộc Cách mạng lần thứ tư dẫn đến sự bùng nổ của các } \\
\text { phương tiện truyền thông ưu việt }\end{array}$ \\
Sự mong muốn được thay đổi môi trường làm việc và \\
tim kiếm thu nhập của nhân lực KH\&CN khi Việt Nam \\
đang dần hội nhập sâu rộng hơn với thế giới
\end{tabular}

\section{THÁCH THỨC (T)}

Hành chính hóa hoạt động khoa học vẫn diễn ra phổ biến

Nhân lực R\&D chưa chủ động tìm kiếm giao dịch và tính cam kết còn chưa cao . Chỉ đáp ứng được nhu cầu của một bộ phận nguồn nhân lực $R \& D$ do các nhóm cung ứng trong nước kém ngoại ngữ, các nhóm cung ứng nước ngoài đòi chi phí cao

Sự phát triển của phương thức tổ chức lao động của nhân lực $R \& D$ gắn với các giải pháp kỹ thuật số là xu hướng phổ biến trên thế giới

\section{Kết luận}

Cuộc Cách mạng Công nghiệp lần thứ tư có tác động mạnh mẽ, chi phối định hướng phát triển khoa học và công nghệ của nhiều quốc gia, trong đó có Việt Nam. UBER nhân lực R\&D là một trong những phương thức tổ chức lao động giả định có nhiều điều kiện để phát triển với sự hỗ trợ đắc lực của các giải pháp kỹ thuật số, gắn Cung - Cầu nhân lực khoa học, góp phần cải thiện tính minh bạch và hiệu quả trong thực hiện các nhiệm vụ khoa học và công nghệ, tăng cường năng lực chủ động, sáng tạo và quốc tế hóa của nguồn nhân lực R\&D trong nước.
Các nhà quản lý còn xem nhẹ sự thay đổi văn hóa và phương thức quản lý vì chưa nhận diện đây là động lực chính của sự đổi mới.

Tính ưu việt của phương thức tổ chức lao động UBER nhân lực R\&D được nhận diện sơ bộ trong phạm vi bài báo của nhóm tác giả, khẳng định những tác động mạnh mẽ của cuộc Cách mạng công nghiệp lần thứ tư trên tất cả các lĩnh vực, đặc biệt trong phát triển khoa học và công nghệ. Qua đó có thể thấy rằng, bền cạnh việc thực thi các biện pháp cụ thể trong sử dụng, thu hút, đào tạo nhân lực khoa học, cũng cần lưu ý về hoạch định các chính sách thúc đẩy sự ra đời của các phương thức tổ chức lao động gắn với các giải pháp kỹ thuật số giúp thúc đẩy di động xã hội của nhân lực khoa học trong thời gian tới. Đây cũng chính là bài toán đặt ra cho các nhà quản lý $\mathrm{KH \& CN}$ về sự hình thành 
phương thức tổ chức lao động mới vượt khỏi biên giới hành chính, có thể dẫn tới những thay đổi về bản chất các mối quan hệ xã hội trong cộng đồng khoa học.

\section{Lời cảm ơn}

Bài viết là kết quả nghiên cứu thuộc đề tài Chính sách quản lý di động xã hội đối với nguồn nhân lực khoa học và công nghệ chất lượng cao của Việt Nam trong bối cảnh hội nhập quốc tế (Mã số KX.01.01/16 - 20) thuộc chương trình khoa học và công nghệ trọng điểm cấp quốc gia giai đoạn 2016 - 2020: "Nghiên cứu những vấn đề trọng yếu về khoa học xã hội và nhân văn phục vụ phát triển kinh tế xã hội” Mã số: KX.01/16 - 20

\section{Tài liệu tham khảo}

[1] Vũ Cao Đàm, (2014). Mốt số vấn đề quản lý khoa học và công nghệ ở nước ta, NXB Khoa học và Kỹ thuật.

[2] Vũ Cao Đàm, (2009). Giáo trình Khoa học luận Đại cương hay là Lý luận về Khoa học và Công nghệ, 2009, Trang 78.

[3] Trung tâm Thông tin KH\&CN quốc gia, Phát triển nhân lực KH\&CN ở các nước ASEAN, Hà Nội, 2005.
[4] Y.de Hemptinne, Những vấn đề then chốt của chính sách khoa học và kỹ thuật. Tài liệu do Trần Đức Quang dịch và Vũ Cao Đàm hiệu đính. Ủy ban Khoa học và Kỹ thuật Nhà nước, Viện Quản lý Khoa học, Hà Nội, 1987, Trang 54.

[5] Đào Thanh Trường, (2016). Di động xã hội của nguồn nhân lực khoa học và công nghệ trong bối cảnh hội nhập quốc tế: Từ lý thuyết đến thực tiên. $\mathrm{Nxb}$. Thế Giới.

[6] Alvin Tofler (1992). Cú sốc tương lai. Nxb. Thông tin lý luận. Hà Nội.

[7] Mai Hà. Hội nhập quốc tế: Một định hướng quan trọng trong hoạt động KH\&CN, Hệ thống khoa học, công ngệ và đổi mới ở Việt Nam trong xu thế hội nhập quốc tế. Nxb. Thế giới. 2015. Tr.79.

[8] Thao Lâm, (2016). Nhận diện cuộc cách mạng công nghiệp thứ 4. Nguồn: http://dantri.com.vn/khoa-hoc-cong-nghe/nhandien-cuoc-cach-mang-cong-nghiep-thu-420161207070725629.htm

[9] Zuopeng Zhang (State University of New York, USA) and Sajjad M. Jasimuddin (Kedge Business School, France), (2016). Pricing Mechanisms for Knowledge Market Online: A Model-Based Analysis. Source Title: Encyclopedia of ECommerce Development, Implementation, and Management.

[10] Lê Xuân Định (Chủ biên) và nhóm nghiên cứu. (2015). Sách Khoa học và công nghệ thế giới tri thức cho phát triển, Nxb. Khoa học Kỹ Thuật, Trang 126.

\title{
Uber-based Research \& Development (R\&D) Human Resource: An Approach to Modern Human Resource Management
}

\author{
Dao Thanh Truong, Nguyen Thi Quynh Anh \\ VNU University of Social Sciences and Humanities, 336 Nguyen Trai, Hanoi, Vietnam
}

\begin{abstract}
In the context of globalization and international integration, the thinking of policy making and policy implementation on social mobility of R\&D human resource has changed. For a long time, "brain drain" and the formation of "magnet countries" attracting huge flows of the "brain" have long been a big threat to a large number of nations. Nowadays, under the impact of the Fourth Industrial Revolution and the more and more flexible mobility of $R \& D$ human resource, $R \& D$ managers have been more and more active in ensuring the conditions to encourage social mobility of
\end{abstract}


$R \& D$ personnel. This paper presents an overview of social mobility of $R \& D$ human resources and the impacts of Revolution 4.0 to draw insights for analyzing the establishment of a new mode of labor organization - Uber-based R\&D human resources. This approach provides policy implications for social mobility management of R\&D human resources and encourages the promoting of human innovative capacity to contribute to a comprehensive development of all nations.

Key words: Research and Development (R\&D), R\&D human resources, social mobility of R\&D human resources, Uber-based R\&D human resources 